\title{
Aesthetic Philosophy of Art Resilience as a Global Art Movement and its Impact on Contemporary Interior Design
}

\author{
Mahmoud Ahmed Hassan Elkouriny \\ Assistant Professor at Helwan University - Faculty of Applied Arts \\ Department of Interior Design \& Furniture. Egypt
}

2019

\section{Introduction:}

Both creative and technical aspects of interior design are influenced by contemporary global art movements and trends. Some of these movements and trends are exaggerated to the point of fantasia, others are applicable, objective and influential to societal advancement, taking into account cultural identity and ruling standards. Of those trends that express the latter is Art Resilience, founded in Paris in 2014, the birthplace of most modern movements of the world. It was natural for the movement to have an effect on modern and contemporary architecture and interior design concepts in terms of their creative and applied aspects. This is due to the movement's interest in reestablishing the aesthetic values of artistic work and design, in light of the current cultural and social developments.

This paper aims to shed light on how this movement and its principles impacted interior design.

\section{Why This Research:}

Interior design is the life we live in. It is what surrounds us from furniture, colors, materials, walls, windows, doors, and everything we build and use. Therefore, all that we see, either positive or negative things, affects us respectively whenever we utilize this vacuum, influenced by contemporary intellectual trends and artistic movements. At the present moment, one of most important and globally transcending contemporary intellectual and artistic movements, Influential in art, architecture and interior design, is the Art Resilience movement. Therefore, we must shed light on this artistic movement to emphasize its pros and cons to the interior designer.

\section{Research Problem:}

- The emergence of some works of interior design express the taste of its interior designer without taking into account the ruling concepts and aesthetic dimension, also neglecting cultural heritage. All the aforementioned go against the Art Resilience movement's concepts and must be highlighted.

- Deficiency for some due to limited knowledge of modern art movements and how to benefit from them.

- In some contemporary art designs, we see the disappearance of the work of art, because these designs are unfounded and do not distinguish themselves in any way from anything else. Modern icons triumphed. Being a token is to be against the world. To be against the world means to be against reason, and therefore against humanity and ruling concepts.

\section{Research Objective:}


Shed light on the most important contemporary international artistic and intellectual movements to benefit from them in interior design, specifically in this paper, the contemporary Art Resilience movement, to raise the level of creativity of the interior designer to keep pace with contemporary thought.

\title{
Research Hypotheses:
}

- Art is an expression of consciousness of existence, and beauty is its basis.

- Interior design as an artistic product influenced by artistic and intellectual movements.

- Interior design as a work of art is measurable and applicable.

- Interior design, as any other branch of the arts, must represent the community and link the simple user and the community, and not overlook the introduction of what's new as well as the redevelopment of the user to cope with global intellectual fluctuations.

\section{Art Resilience in Paris:}

The Art Resilience movement was created in 2014 by Ksenia Milicevic and founding members John Botica, Gregorio Cuartas, Christel Larson, Girr Lartigue, Victor Molev, Miguel Betancourt, Senol Sak and Christopher Stone. They are a group of artists who consider art and design as being a product of a creative and systematic intellectual process, built on foundations and rules, and not merely on the birth of the moment, without a codified dimension. And being a work of art hence it is measurable and applicable. Artists are part of contemporary reality and are not separated from the world, hence must be influenced by the intellectual and social changes and concepts governing society, thus preserving the ability of art and design to connect man with the world.

\subsection{Defining the Concept of "Resillience":}

\begin{abstract}
"Resilience" is a very old and very modern concept. It was used during ancient times in writings on portico, from Seneca ${ }^{1}$, Pliny ${ }^{2}$, Cicero ${ }^{3}$, The term "Resilience" comes from the Latin verb "resilio", which means "to leap or spring back", so it is used as "rebound, resistant". In most cases, "Resilience" will now be defined as the ability to recover in spite of shocks, disasters or hardships, and in a time of globalization and clash of civilizations this term floats frequently.
\end{abstract}

\section{Originally, the term was used in metallurgy, which refers to the quality of the material manifested in its ability to revert to its initial state after shock or constant pressure. The metal, which is under strong pressure, makes it}

\footnotetext{
${ }^{1}$ Seneca the Younger (died April 12, 65 AD), fully Lucius Annaeus Seneca and also known simply as Seneca, was a Roman Stoic philosopher, statesman, dramatist, and-in one work-satirist of the Silver Age of Latin literature. Seneca was born in Córdoba in Hispania, and raised in Rome, where he was trained in rhetoric and philosophy.

2 Pliny the Elder (23 AD - August 25, 79 AD), fully Gaius Plinius Secundus, was a Roman author, a naturalist and natural philosopher, a naval and army commander of the early Roman Empire, and a friend of emperor Vespasian. Pliny wrote the encyclopedic Naturalis Historia, which became an editorial model for encyclopedias.
}

${ }^{3}$ Cicero (January 3, 106 BC - December 7, 43 BC), fully Marcus Tullius Cicero, was a Roman statesman, orator, lawyer and philosopher, who served as consul in the year $63 \mathrm{BC}$. He came from a wealthy municipal family of the Roman equestrian order, and is considered one of Rome's greatest orators and prose stylists. 
distortable and is able to regain its shape. "Resilience" then extended to the ability of individuals and groups to continue to evolve despite destabilizing, difficult or painful events.

\begin{abstract}
This term was first used in 1955 by Amy Werner in Hawaii who studied children in hardship. She tried to understand what factors allowed these children to rebuild and live a balanced life. Psychological studies have examined this and a number of factors have emerged: the ability to solve problems, individual qualities such as self-knowledge, autonomy, self-esteem, trust, altruism, social communication and the ability to find support.
\end{abstract}

In fact, it is a matter of developing these qualities in individuals to overcome trauma or prepare them to respond in crisis situations, in this sense, studies are conducted in psychology, but the concept of "resilience", for ten years, has been applied in many areas such as business organization, environment, architecture, interior design, computer science, medicine, and education.

\title{
3.1 Recent Emergence of Art Resilience:
}

Art Resilience movement emerged as a reaction to the intensity of the emergence of Alana and increased privacy in some modern trends in architecture, design and art. The movement emphasizes the aesthetic values in the work of art through aesthetics, which makes the work or design unique and clearly visible from any other design that lacks the foundations of aesthetics, while maintaining the identity of the designer and design.

The movement calls for adapting to cultural, social and political changes in art and design without neglecting the role of aesthetics and the principles of art, and preserving the cultural heritage.

The late $19^{\text {th }}$ and $20^{\text {th }}$ centuries saw the birth of artistic movements such as symbolism, cubism and surrealism that sought to adapt to the great social, industrial, economic and political changes that took place at the time. Parallel to these movements are a series of some of the strangest movements such as Hirsutes, Hydropathes, Incohérents, and highly politicized and disruptive movements, such as Constructivism, Suprematism, Futurism, and Dada. These movements, together with the aesthetics of the Anglo-Saxon analysis of the 1950s which are characterized by the rejection of the idea of beauty as the basis of art, call for questioning the existence of works of art as a specific human achievement (Arthur Danto,2015)

Resilience in art tends to restore beauty as the foundation of art.

The beauty, by its proximity to the good, allows judgement about quality, when discerning whether "this is good" or "this is not good." A work that is not based on any foundation is beyond the possibility of appreciation of any quality. The quality of the work is in its approximation of what art is supposed to be, that is, mainly, a producer of aesthetic emotion. Every work of art is rich in possibilities for expression, demonstration, and discourses which call upon our feelings, and yet, the only judgement on quality possible is through the beauty, that is to say, the internal structure of the work. It is from this structure that it differs from ordinary discourse. The judgement of the quality of a work is essential, because art is formational(Ksenia Milicevic,2016). 

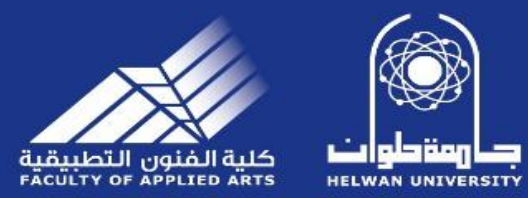
www.dsaajournal.com

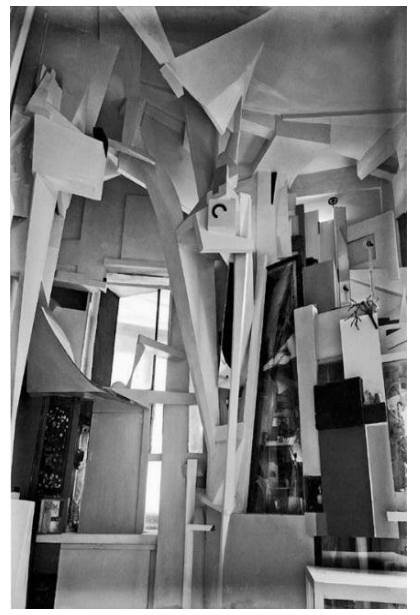

Image - [1]

Courtesy of Kurt Schwitters (original 1933 photograph)

An internal vacuum characterized by chaos and a high uplift of the designer person ... Interior design is not purely human relations of the designer alone.
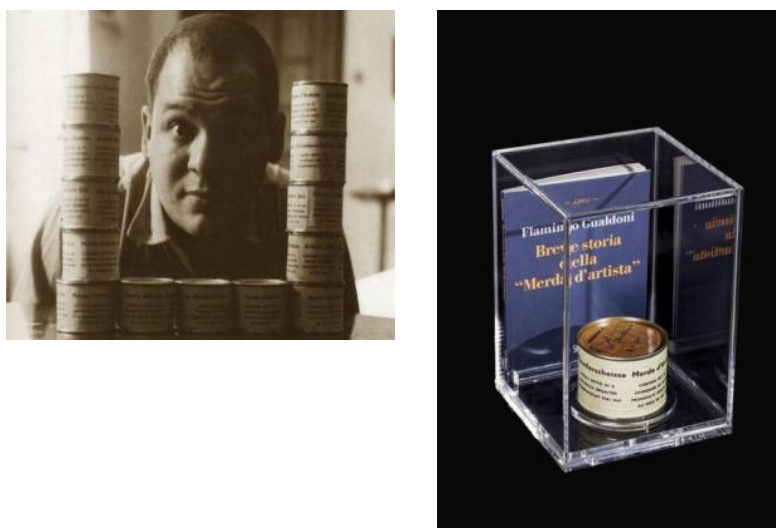

Image - $[2,3]$

\section{Piero Manzoni}

A clear example of a comical egotistical nature of an artist without regard to the standards governing aesthetics.

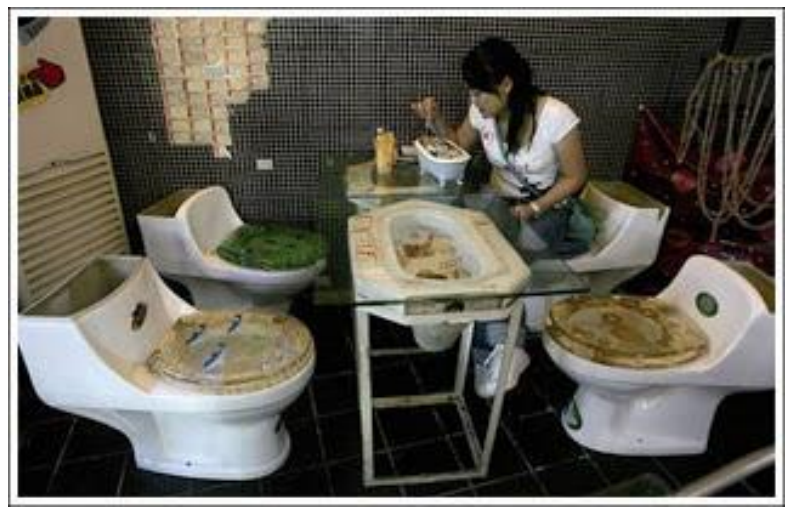

Image - [4]

\section{Modern Toilet}

is a unique bathroom-themed restaurant chain with several locations located in Hong Kong and Taiwan

Everything in the 2,800-square-foot $\left(260 \mathrm{~m}^{2}\right)$, three-story restaurant is based on items from a bathroom. The checkered tile covered walls are adorned with showerheads, while plungers hang from the ceiling along with fæces-shaped lights. The chairs are actual unworking toilets, dishes are served on plastic miniature toilet bowls, and drinks in miniature urinals. 

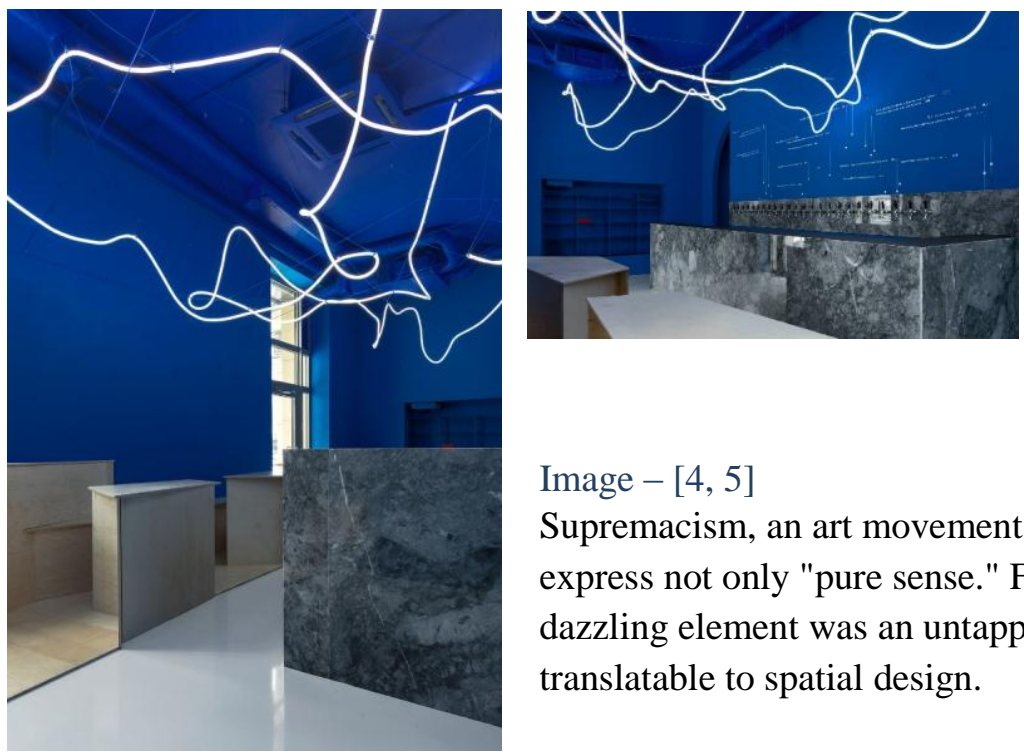

Image $-[4,5]$

Supremacism, an art movement founded by Kazimir Malevich, seeks to express not only "pure sense." For the Russian studio Monoloko Design, the dazzling element was an untapped visual language with qualities not translatable to spatial design.

When contemporary art relies solely on the artist's intention, the artist's resilience determines his responsibility to society, because art is the future "image" of society and acts in parallel with its cohesion. Man is a social being, by nature must live in society to exist, excessive individualism is impossible, these two sides must be harmoniously combined.

\section{The Groal of Art Resillience:}

Flexibility is a movement that seeks to redefine the concept of art and design during the contemporary period and uphold the values of aesthetics and emphasize the balance in design and artwork between ego (privacypersonality of the designer) and the principles of aesthetics and values, taking into account current intellectual, social and political changes.

In theory, rather than a split approach, resilience is a systematic approach. In practice, resilience removes discourse that hinders artistic production and focuses on work development.

Given that the quality of the artwork can be objectively determined, the flexibility of the art excludes purely random, gestural, ugly, conceptual or only decorative productions. Design (artwork) consists of aesthetic and ethical systems. We can rationally judge the aesthetic quality of the work, and we can perceive it with our sensitivity in the "readable" part, in what it "speaks" or what provokes it.

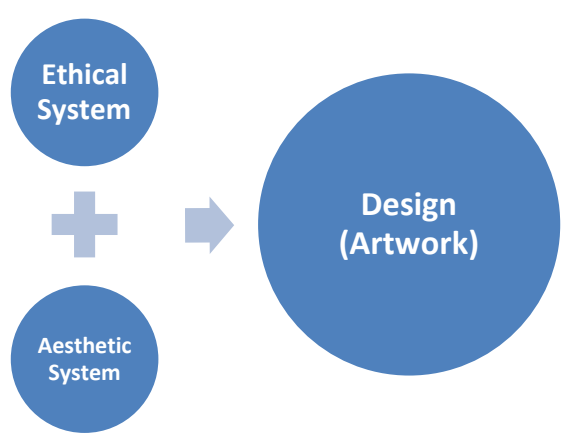

\section{Figure - [1]}

Explains how to judge design through the availability of two prerequisites: the aesthetic system and the ethical system. 

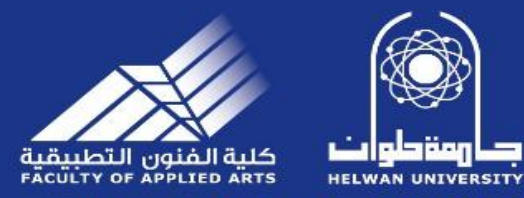

Volume 1. Number 1 . January 2020

\subsection{Aesthetic System:}

It is all about the aesthetic values in the design, especially the personality of the designer or artist, including all that's extraordinary and exaggeration.

\subsection{Ethical System:}

It is the method of presenting the design to the community where it must have authenticity and identity, usability and applicability, taking into account the concepts governing society spatially and temporally.

On a general level, resilience requires a variety of expressions rather than contemporary art production, which for decades has produced images that are immediately recognizable as "contemporary art" and ended up in only exhibition halls and office shelves rejecting any other form of art as old.

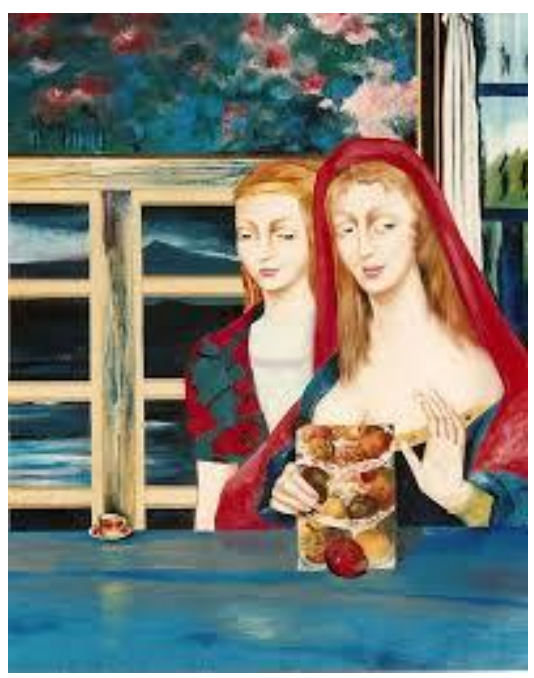

Image - [7]

La quete incertaine

Painting by Ksenia Milicevic

Great example for Art Resilience which reflect: art is not the result of a random gesture nor a dramatic or sealed entertainment for the public. The artists whose work are part of the contemporaneity, but which are based on aesthetics, thus maintaining its ability to link man with the world.

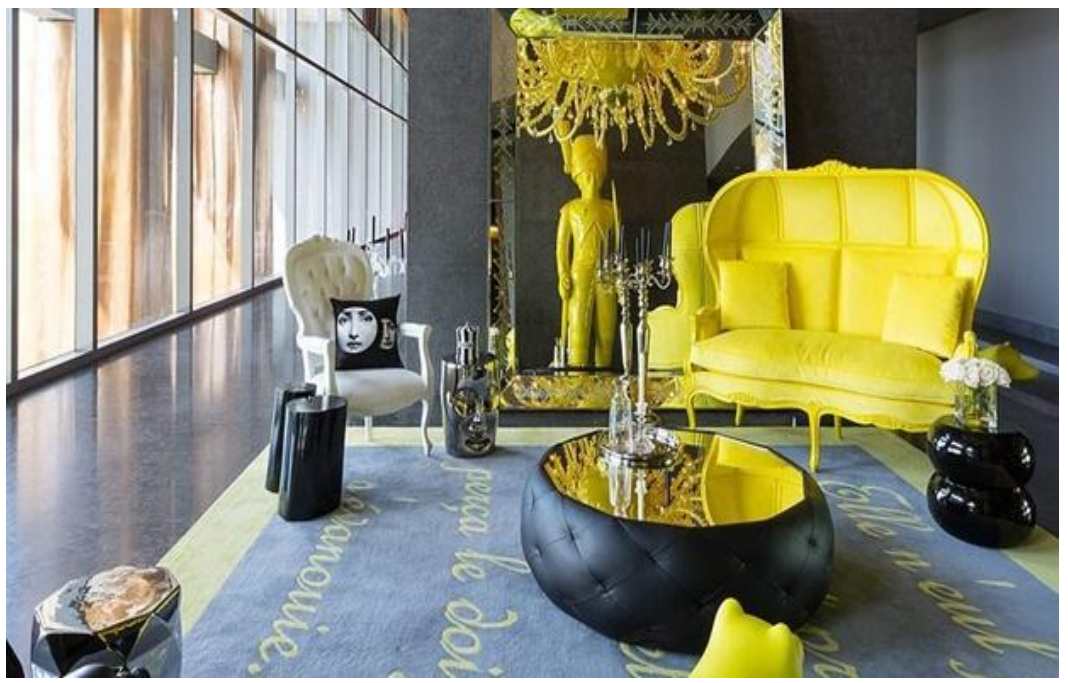

Image - [8]

Philippe Starck is one of the best interior designers in the world and his style is remarkable, an example for:

- The definition of art to be possible. Beauty to be objective and the natural foundation of art.

- The formal expression must be free, but based on aesthetics that ensures quality. Artists must be aware and responsible for their actions.

- Art to be key to community and individual development. 

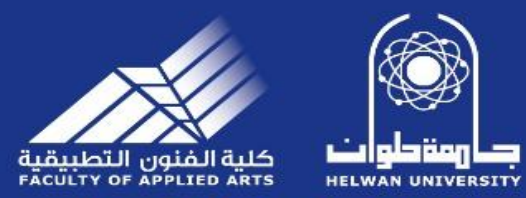

Volume 1. Number 1 . January 2020

Image $-[6,7,8,9]$

Basouna Mosque: Suhag Governorate, Egypt

Designer: Walid Arafa 2015

\section{National exampel}

The formation of the new mosque and the diligence of the designer to establish the true image of architecture and design in the service of society, and its role in the re-creation of civilization and human development, that successful architecture is in harmony with nature and the universe "and chants praise" the case of all creatures, so the challenge was "how to design a building that does not contradict nature". Great example and application of the philosophy of art resilience.
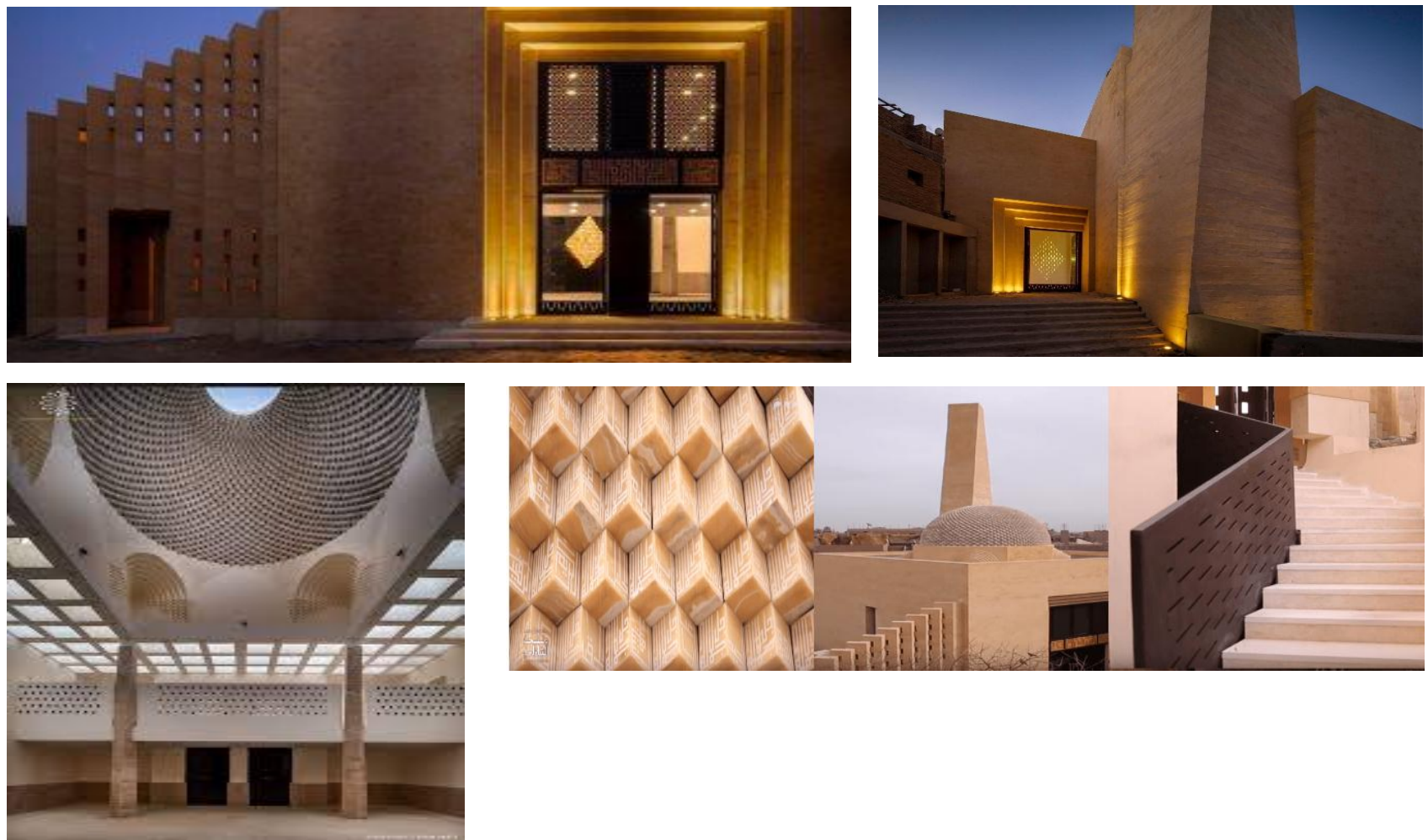

All cultures generate images of themselves through artistic imagery, but not all artistic images are works of art. Contemporary art that assumes itself as a current art may be a picture of us, but resilience is necessary when it comes to its quality as an art.

\section{Principles of Art Resilience Movement:}

- Redefining art and design to be possible for everyone. 
- Objectivity of beauty and the emphasis of it being the basis of art and design.

- Both the artist and the designer are responsible for presenting their works under the aesthetics of art and design and not comical and personal passions without neglecting the personality of the artist and designer.

- Art and design are key to community and individual development.

\section{Aesthetic Philosophy of the Art Resilience Movement:}

Beauty is basically seen as a simple matter of taste. Any objective value is rejected. But what the movement affirms is that beauty is not in the subject, nor in form or color, but is subject to the work itself, it embraces it, and emerges from it, from its form in its entirety and not from the beauty of what it represents.

The art resilience movement interprets the stage of perception and judgment on design as follows. A vision of all (ontology ${ }^{4}$ ) appears where the subject (viewer) and the object (work) are one entity. At that moment, there is no space for a simple taste, but the life experience of both the designer and the recipient is reflected(Edgar Morin,1977).

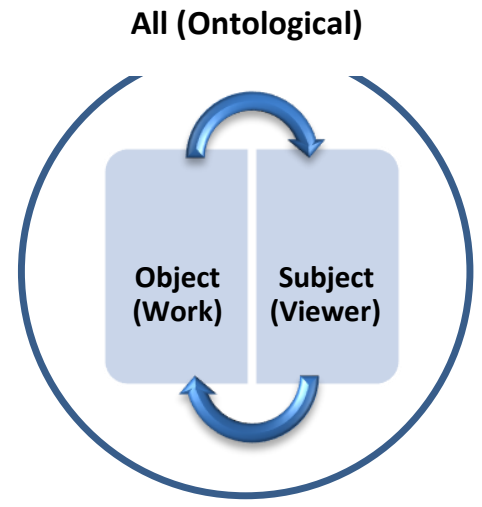

Figure - [2]

The contemporary beauty from the point of view of the art resilience movement is to see the ontological whole where the subject (viewer) and the object (work) are one and indivisible unit.

Only the period in which the work registers itself is canceled and artistic products become ephemeral. Through subjectivity, production is focused solely on the artist's works, where the interest of the artistic component lies solely in the intention of connoting the artists' project. However, it is precisely art that has no intention

\subsection{The Concept of Beauty in Art Resilience:}

Beauty is a network with rules but unfolds infinitely, represented by elements (experience, memory, folklore, etc.) which are mechanisms of acculturation, and then a stage of brainstorming using cultural and social changes, and mechanisms of beauty as the designer must ensure the idea of two aspects: the first one allows the activation of the experiment to be broad and potentially interpretable (the personal character) to the designer so as to be concerned

\footnotetext{
${ }^{5}$ Ontology: in Greek, meaning "Being", is one of the most original and important branches of metaphysics. This study examines the nature of intangible existence in metaphysical issues arising from scientific perceptions or concepts and laws, such as matter, energy, time, space, quantity, quality, reason, law, mental existence, etc. And find any entity or entities and any patterns of these entities in life. However, ontology is closely related to the terminology of reality.
} 
with the direct superficial meaning, while the second is concerned with the deep structure, the ruling concept (the fundamentals of beauty, societal character, measurable and applicable) that lets the work as it stands.

Art is the trend towards life. In the universe, everything oscillates between "construction" and "demolition." This is the rhythm of the world. Human societies periodically oscillate throughout history between war and peace. Art calls for life. Beauty is harmony, calm and balance. It is the natural foundation and purpose of the insoluble unit of work.

\subsection{Idea and Concept in Art Resilience Movement:}

Ideas are hazy entities, cognitively incomplete, because they are self-conscious states reflective of a purely individual human vision and have differentiation and specificity, revolve around specific topics, realistic or distant from reality (fictional), always carry variable qualities In the context of the cognitive field that embraces it, and from the previous perspective is a self-vision of the designer (organizational approach) on the signs of what he had in himself, and it becomes a thought that can be traced when converted according to scientific development of professional knowledge to philosophy (the image of the concept of explanation of the idea and self-perceptions), based on rules that can be shown abstractly in design gravitating towards reality.

The concept is a perceived visual cognitive unit, with a system, and flexible and dynamic mobile templates that accept expansion and reception, in which the chosen and isolated perceptions of the designer appear to show facts that are specific to him, wandering in his mind. Also, concepts are open to add any value/or values and expands with the expansion of the designer. Ideas and philosophy are components of one organism, cannot be separated from each other.

\subsection{The Concept of Aesthetic Perception in Art Resilience Movement:}

The concept of aesthetic perception of the movement is purely scientific. Neuroscience, dives into this vital question for humans. Faced with artwork, there is no neutral observation. Thanks to recent research through medical imagery, it is possible to separate the emotional reactions associated with pleasure or resentment, and other aesthetic appreciation, when facing beauty.

During experiments in which people were placed in front of art objects, researchers discovered that two different circles of the brain were activated: the improved cortical circuit and insulin, and the emotional circuit and the amygdala. When experiments were conducted to measure reactions to artworks created according to the golden ratio by showing antique themes and Renaissance sculptures, scientist found that everyone relates fittingly to harmonious proportions. Everyone sees harmony and balance in a work of art. The same circuits become active that evolving cortical circuit. Responses are very fast, almost instantaneous. Soon after, the deeper and older areas that include emotions are activated. After that, our experiences, memories and mental states are activated, here's a second answer: I like it, or I don't like it. We must distinguish, on the one hand, the objective beauty associated with harmonious forms and physically measurable relationships, and on the other hand, "personal perception" (I love it - I do not like it). 
Figure $-[3]$

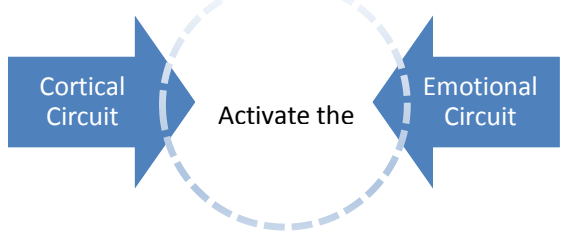

Design Perception

Image - [10]

Furniture piece by designer Khaled Mehrez

The story of the prophet David and the Hoopoe through elements (experience, memory, or popular heritage) of mechanisms of acculturation. A Production piece of furniture from this story.
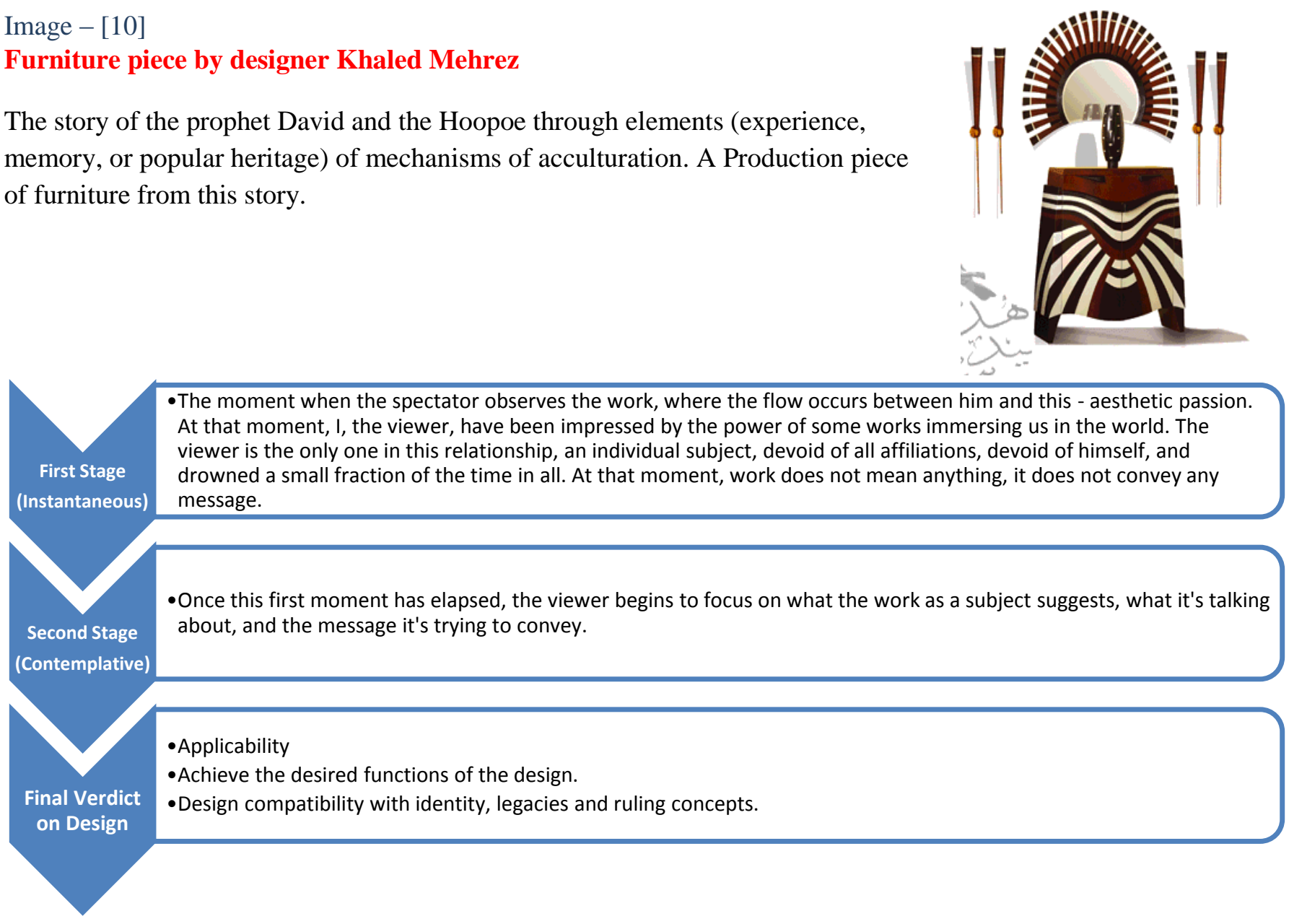

Figure - [4]

This diagram explains that the contemplation of a work of art or design, according to the art resilience concept, takes place in two stages taking into account the presence of two necessary elements in the design. The first is the need to re-enter the idea of beauty in art without which there is no art. The second is to re-establish what's beautiful. The beauty of artwork from the art resilience movement point of view is not in the subject, nor in form, nor in color, but in what is subject to work, measurement, and application.

The freedom of creativity of the artist is a continuation of the creation of nature. This reflects the essence of modern-day art, which "becomes a form of social consciousness that enjoys freedom and relative independence". 
Hence, the saying "the aesthetic characteristic of the modern era and not the beautiful saying which is an advantage of the old stage" and the difference is related to the extent of acquiring freedom.

Even to the extent that the creator is regarded as the origin of the work and as much as the creative work is an expression of the original if we see the originality of the artistic creativity of the creators through their creative achievements and their freedom of thought and performance. What does the creative artist and traditional craftsman meet or disagree with?

\section{Research Results:}

- Art and design are an integral part of the surrounding community.

- Beauty is a network with rules but unfolds infinitely.

- Both the artist and the designer are responsible for presenting their works under the aesthetics of art and design and not comical representations and personal passions without neglecting the personality of the artist and designer.

- Art and design are key to community and individual development.

- Design (artwork), consists of aesthetic and ethical system.

- Art and design are the products of a creative and systematic intellectual process built on foundations and rules and not the result of the moment without a codified dimension, and as a work of art, is measurable and applicable.

- All cultures generate images of themselves through artistic imagery, but not all artistic images are works of art. Contemporary art that assumes itself as a current art may be a picture of society, but resilience is necessary when it comes to its quality as art and design.

- Art Resilience movement calls to the adaptation to cultural, social and political changes in art and design without ignoring the role of aesthetics and the basics of art and the preservation of cultural heritage.

\section{Research Recommendations:}

- To shed light on contemporary art movements to evaluate them and draw all that is positive and in the interest of art and design.

- Design must be logical, measurable and applicable.

- Put the ruling concepts towards our eyes as designers without neglecting the character of the artist and designer. 


\section{References}

(1) Alain Besancon, L'image interdite, Librairie Colibrio (BESSENAY , France) (2000),

(2) Arthur Danto, " After the end of art", Princeton University Press, (2015)

(3) Edgar Morin, La méthode, I. La Nature de la Nature, Seuil, 1977,

\section{Sites:}

https://www.art-resilience.com/english/factors-of-resilience-in-art/

https://www.artmajeur.com/en/kseniamilicevic/artworks/3434752/la-quete-incertaine

https://www.roomdecorideas.eu/how-to-combine-different-interior-design-styles-like-philippe-starck/

National seminar on arts resilience, UK, http://artsdevelopmentuk.org/presentations-from-the-aduk-national-seminar-onarts-resilience-2016/ 